\title{
Special features of human retinal angiogenesis
}

\begin{abstract}
This review focuses on aspects of primate retinal vasculature that are not found in lower mammals, with emphasis on development of vascular patterning, the foveal avascular zone (FAZ), and pathogenesis of retinopathy of prematurity. Uniquely primate features arise from primate-specific neurovascular and neuroglial relationships. Although experimentation in primate vascular development is relatively impractical, it affords insights into normal and pathological retinal angiogenesis that is difficult to approach in other ways.

Eye (2010) 24, 401-407; doi:10.1038/eye.2009.324; published online 15 January 2010
\end{abstract}

Keywords: angiogenesis; development; human; monkey; foveal avascular zone; retinopathy of prematurity

Differences in retinal vascular development and vascular pathologies across species illuminate important issues in angiogenesis and angiogenic therapy. In particular, primate intraretinal vasculature differs from that of common experimental animals with regard to vascular patterning, neurovascular and neuroglial relationships, and endogenous angiogenic and antiangiogenic mechanisms. Below we present several features that are unique to primates, with emphasis on the foveal avascular zone (FAZ) and the ridge in retinopathy of prematurity.

\section{Anatomy and development}

Retinal blood vessels in primates form a fourlobed pattern along the major vascular arcades, and do not appreciably cross the horizontal raphe. ${ }^{1}$ Nasal-temporal retinal asymmetry is absent primarily because of the contour of perifoveal vessels. Ganglion cell axon bundles and an astrocytic plexus in the nerve fibre layer
RF Gariano

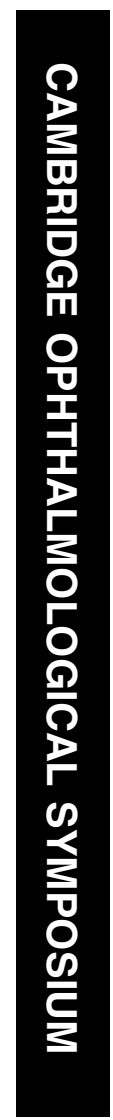

(NFL) show a similar pattern (Figure 1). Murine retinal vessels, in contrast, are simply radially organized, without reference to a horizontal midline or macula (Figure 1).

Intraretinal capillary plexuses in several species are similarly situated in the NFL and on either side of the inner nuclear layer. Primates show an additional plexus in the ganglion cell layer. In addition, all lamina extend from the optic nerve head nearly to the ora in mice, whereas in primates only the most superficial plexus (in the NFL) persists in the periphery, and the deeper layers extend progressively less peripherally., In all species, the outer retina (outer plexiform and nuclear layers, photoreceptor inner and outer segments) is normally avascular. Primates also show a conspicuous avascular zone centred on the fovea, and a small avascular region just posterior to the ora serrata; in both these regions, the capillaries bordering the avascular zone link up in a continuous arcade.

During development, retinal vessels arise adjacent to the optic nerve head and extend peripherally within the superficial retina. As this superficial plexus reaches its peripheral most extent, it sends vertical sprouts towards outer retina to generate the plexuses bordering the INL. ${ }^{1,3}$ In humans, formation of deeper plexuses follows the same posterior-to-anterior vector, whereas in mice deeper vessels seem to arise simultaneously from inner vessels throughout the retina. $^{2-4}$ Retinal vascularization begins before midgestation and is nearly complete at birth in primates, whereas in mice it begins at birth and is generally completed within 3 weeks. ${ }^{1,3}$

In mice, a series of reciprocal interactions between ganglion cells, astrocytes, and vessels has been described, which suggest that ganglion cells and astrocytes provide a blueprint for subsequent retinal vascularization. ${ }^{5}$ In brief, ganglion cells stimulate glial growth by release of PDGF-A that exerts an effect on astrocytic receptors to provide attractant and mitotic cues. Astrocytes thus extend roughly along axonal
Department of

Ophthalmology, Stanford University School of Medicine, Palo Alto, CA, USA

Correspondence:

RF Gariano,

Department of

Ophthalmology,

Stanford University School

of Medicine,

Room A157,

300 Pasteur Drive, Palo Alto,

CA 94305, USA

Tel: + 650743 3477;

Fax: +4088857166

E-mail: rgariano@

stanford.edu

Received: 2 November 2009 Accepted: 17 November 2009

Published online:

15 January 2010

Previously presented at the Cambridge Ophthalmology Symposium, September, 2009 

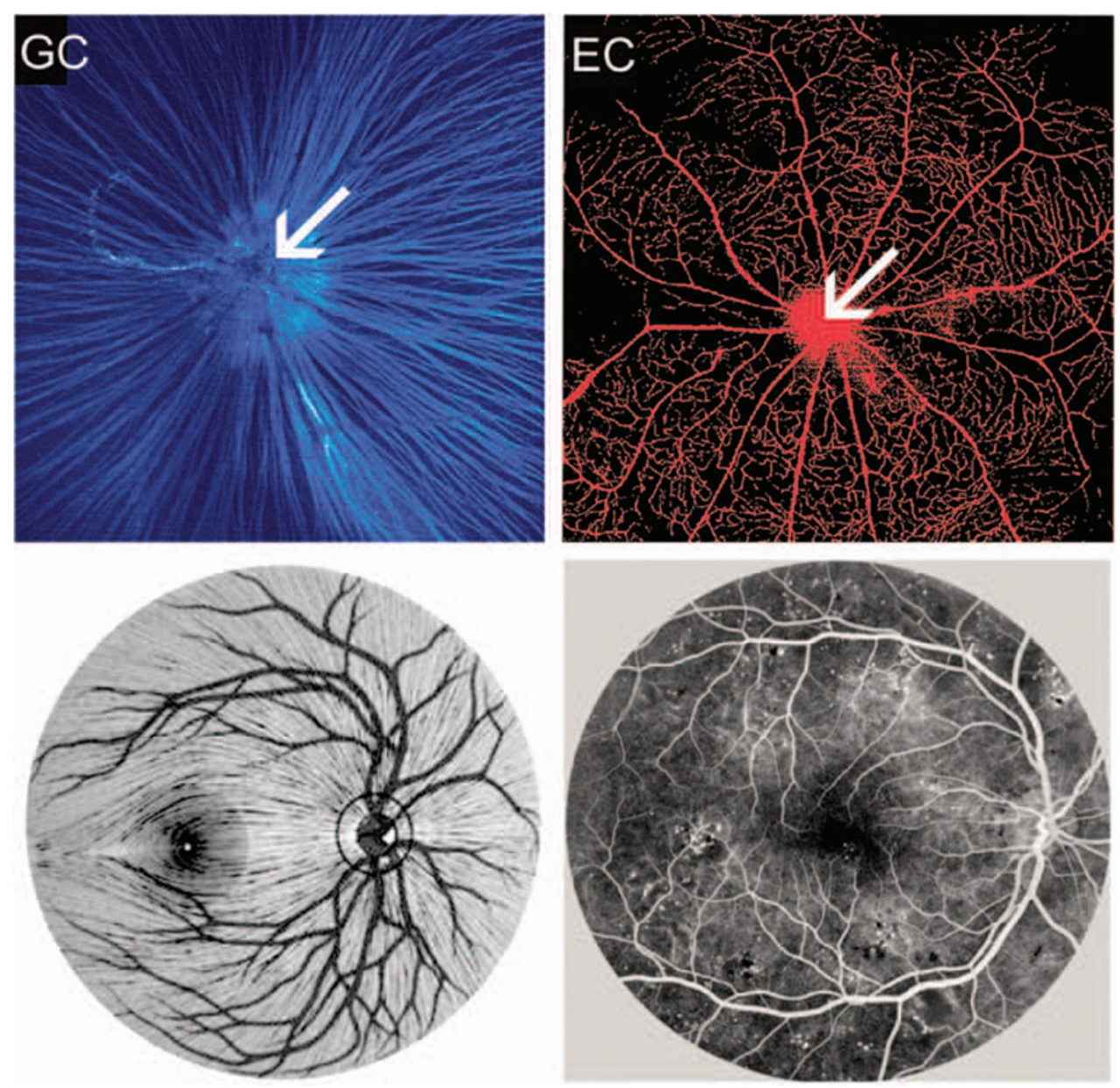

Figure 1 Neurovascular patterning in mice and human retina. Top row: Immunolabelled, ganglion cell axons (GC, left), vascular endothelial cells (EC, right), and astrocytes (not shown) in the adult mouse show simple radial symmetry around the optic nerve head (arrows). Bottom row: The human nerve fibre layer (left, schematic) shows superior-inferior symmetry, and axons skirt around the fovea. Similarly, retinal blood vessels (right, FA, flourescein angiogram) respect the horizontal midline and are absent around the fovea.

lines but proliferate and spread out by contact spacing to form a honeycombed meshwork of cells and processes. ${ }^{6}$ The glial meshwork in turn seems to provide both mitotic and guidance cues to the nascent endothelial sprouts. Astrocytes at the leading edge of vascularization synthesize vascular endothelial growth factor (VEGF) that promotes and directs filipodial extension from the leading endothelial 'tip' cells of growing vessels (Figure 2a). ${ }^{7}$ Filipodia that align with astrocytic fibres may be stabilized by R-cadherin interactions, so that vessels roughly recapitulate the meshwork pattern previously established by astrocytes. ${ }^{4,7}$ Astrocytes at the leading edge of vessel extension also regulate extracellular matrix components that guide radial and vertical vessels growth; for example, glial fibronectin synthesis under the control of the tlx receptor is critical for retinal vascularization. ${ }^{8}$ Finally, new vessels in turn attract pericytes precursors, perhaps from an endothelial precursor pool. All these cell-cell interactions are reciprocal; astrocytes enhance vascular growth and guidance, and, as vessels extend further into the astrocytic plexus they promote glial and ganglion cell maturation. ${ }^{5,7}$ Similarly, pericyte coverage stabilizes new vessels. ${ }^{9}$ Ganglion cells also produce VEGF ${ }^{10,11}$ and may thus regulate vascularization directly, without the intercession of astrocytes.

Cellular mechanisms of blood vessel formation include vasculogenesis, a de novo formation of vessels by linkage of endothelial precursor cells that form the initial foetal vessel segments, and sprouting angiogenesis, in which new vessels arise by sprouting from formed vessels. ${ }^{12}$ The initial studies of Michaelson ${ }^{13}$ of human retinal vascular development using India ink perfusion showed a 'brush border' at the tip of advancing vessels that he interpreted as angiogenic sprouting. Using glycogen and Nissl stains, Ashton ${ }^{14}$ found a collection of 

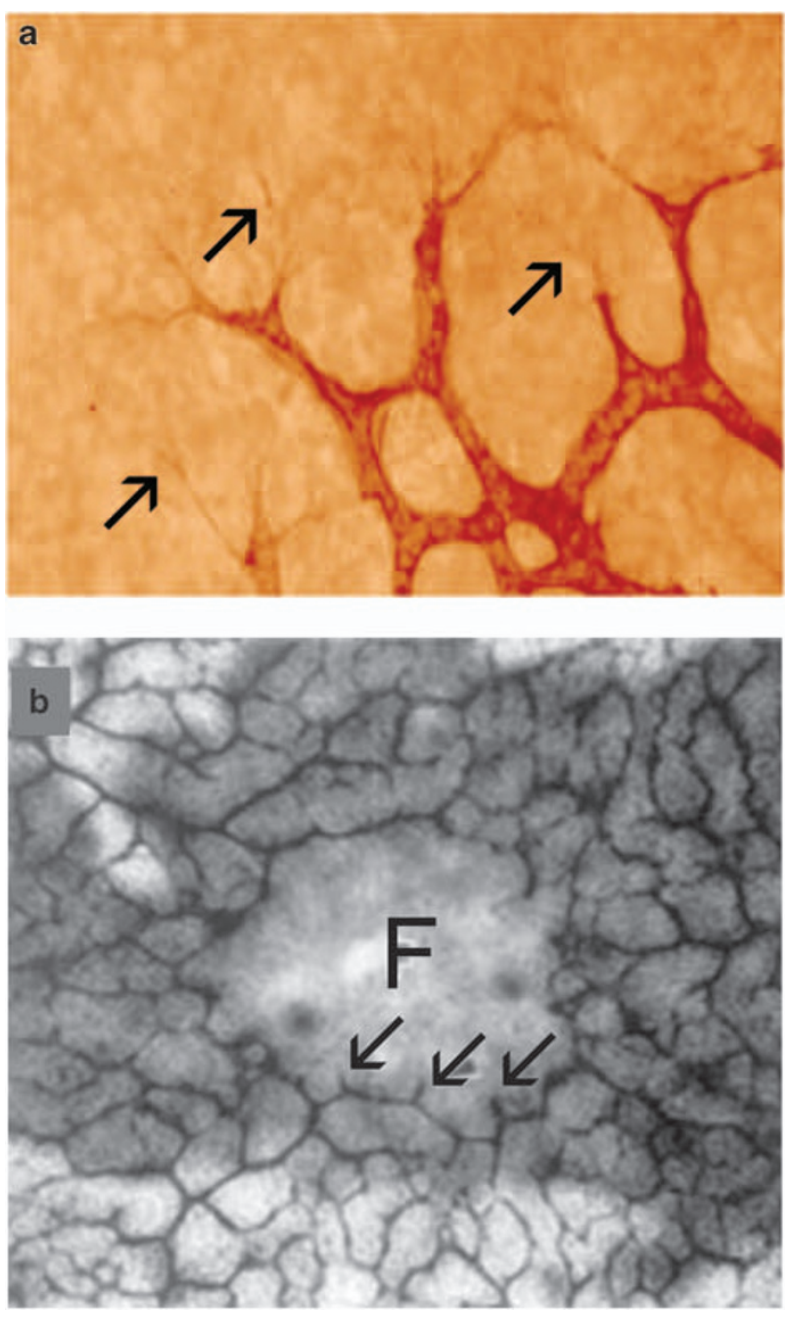

Figure 2 Filipodial extensions from developing primate retinal blood vessels. (a) Foetal age 72-day monkey retinal wholemount showing CD310 immunoreactive several fine filipodial processes (arrows) extending relatively long distances from the tips of growing vessels. (b) Foetal age 120-day monkey wholemount centred on the fovea (F) showing short blunt filipodia that barely enter the foveal avascular area (arrows).

spindle-shaped cells just anterior to growing vessels that often appeared to form cords or a meshwork contiguous with the vessels. He postulated that spindle cells are mesenchymal vascular precursor cells that link up in cords and then lumenize; that is, vasculogenesis.

We and others ${ }^{15,16}$ found that in monkeys and humans these spindle cells are actually GFAP-positive astrocytes that grow ahead of the vasculature, and that, further, the growing vessel tips extend by sprouting, a conclusion replicated in mice. ${ }^{4,7,17}$ Fruttiger ${ }^{17}$ showed that cells ahead of growing vessels in mice were entirely astrocytes, thus directly controverting Ashton's hypothesis. However, the possibility that vascular precursor cells participate in human retinal vascularization was recently revived by the identification of two cell populations that seem to align in cord-like structures in the inner retina. The first is a small pool of cells that express the vessel marker VEGF receptor 2 and lay just beyond growing vessels in the earliest phases of retinal vascularization; ${ }^{18}$ the second population expresses ADPase and CXCR4 but not other typical endothelial precursor markers and appear several weeks before the arrival of blood vessels in the retina. ${ }^{19}$ As these cells have not been found in mice, it remains possible that human retina uses cellular elements for vessel growth that are not operative in mice.

\section{The foveal avascular zone}

The presence of FAZ in primates underscores the extraordinary specializations of the fovea for fine visual acuity. Approximately $40 \%$ of incident photons encounter intraretinal vessels in the extrafoveal macula, and retinal vessels cast shadows upon underlying photoreceptors that produce 'angioscotomas' in the striate cortex. ${ }^{20,21}$

Early investigators thought that the presumptive fovea was initially vascularized, but that vessels then degenerated to leave an avascular zone. Engerman ${ }^{22}$ long ago provided contrary evidence, and we and others ${ }^{2,23}$ firmly established in monkeys and humans that the presumptive fovea is never vascularized, and that radially growing vessels simply skirt around it. Foveal avascularity precedes formation of the foveal pit and mature foveal cone mosaics and circuitry. ${ }^{24}$ It thus seems that avascularity is of primary importance there, and that foveal neuronal specializations may arise at least in part to accommodate reduced perfusion there. ${ }^{25}$ How does this happen?

Flower et $a l^{26}$ have consistently stressed the importance of 'cystic spaces' in the NFL through which vascular structures migrate during development. The NFL in the presumptive fovea is especially thin and lacks cystic spaces, suggesting that the fovea lacks the proper structural milieu for vessel growth. Astrocytes also fail to spread through the presumptive fovea, ${ }^{15,27}$ and their absence may further preclude subsequent vascularization. But the fovea remains avascular during development despite enrichment of ganglion cells there that robustly synthesize VEGF. ${ }^{28}$ A possible explanation for this paradox is that filipodial extension by endothelial tip cells depends critically on the VEGF gradient: a steep gradient promotes extension, whereas a flatter gradient - even in the presence of elevated VEGF concentrations - inhibits extension. ${ }^{7}$ Possibly, as developing retinal vessels enter the roughly circular ganglion cell-rich presumptive fovea, they encounter a 'VEGF bath' ${ }^{5}$ with a shallow gradient. Filipodial 
retraction at the FAZ edge would be expected, and has been reported in foetal primate retina ${ }^{2}$ (Figure $2 b$ ). Just peripheral to the rim of this circle, vessels would sense a steep VEGF gradient, and greater vascular profusion is expected. Indeed, retinal capillary density is greatest in the perifovea. ${ }^{29}$

Kozulin et $\mathrm{al}^{30}$ undertook gene array studies in macular and extramacular human foetal retina in an effort to identify molecular factors that participate in formation of the FAZ. Among the large number of genes differentially expressed in the developing macula, they identified several angioinhibitory factors, including the potent antiangiogenic cytokine pigment epithelial-derived factor (PEDF). Subsequent in situ hybridization revealed increased PEDF expression in the ganglion cell layer of presumptive fovea precisely during the same period when developing retinal vessels bypass the central macula. In addition, many axon guidance-related factors are differentially expressed in the macula, including the repellent factor Eph-A6, leading the researchers to suggest that factors that regulate ganglion cell axon distribution in early embryogenesis are re-activated to exclude vessels from the presumptive fovea. ${ }^{30}$

Another possible factor inhibiting foveal vascularization is the concentration in the FAZ of the macular pigments lutein and zeaxanthin. ${ }^{31}$ These carotenoids confer a yellow tint to the central macula, absorb scattered light, and exert an effect as antioxidants and neuroprotectants. A direct antiangiogenic activity of macular pigments has not been shown, although lutein reportedly suppresses experimental angiogenesis indirectly through antioxidative and anti-immune actions. ${ }^{32,33}$ Macular pigments are already present in all layers of the presumptive fovea-particularly in inner and outer plexiform layers - by about 17 weeks of gestation, before the FAZ is established.

Confirming a role of macular pigments in formation of the FAZ is difficult owing to the impracticality of manipulating the primate foetus. However, support for this hypothesis comes from several human developmental disorders with coexisting abnormalities of macular pigments and macular vascularization. Patients with albinism, for example, may lack both luteal pigments and an FAZ, along with failure of foveal maturation and pit formation. ${ }^{34}$ Similar findings have been reported in a non-albinotic patient with Kartenager syndrome, ${ }^{35}$ and the FAZ is smaller or absent in patients with aniridia who lack macular luteal pigments. ${ }^{36}$

Loss of luteal pigments, in particular of zeaxanthin just temporal to the fovea, was recently detected using autofluorescence imaging in adults with idiopathic juxtafoveal telangiectasia type 2 (Figure 3 ). ${ }^{37}$ In this condition, aberrant vessels grow from the inner retina into the normally avascular outer plexiform and outer nuclear layers. ${ }^{38}$ Decline of luteal pigments may herald the onset of telangiectasis in some patients. These findings suggest that macular pigments help to maintain foveal and perifoveal avascularity in the adults. Macular pigment density in the central retina can be augmented with dietary supplementation, ${ }^{39}$ suggesting a simple means for inhibiting macular telangiectasis.

\section{Retinopathy of prematurity}

Retinopathy of prematurity (ROP) is the most common and best-studied disorder of retinal vascular development, and is a leading cause of blindness in infants. In babies with ROP, high inspired oxygen levels arrest the normal outward growth of blood vessels so that a demarcation line appears between posterior vascularized and anterior avascular retina (stage 1). In some patients, this border may thicken into an ophthalmoscopically visible ridge (stage 2), posterior to which blood vessels anastomose. The ridge is a critical structure in ROP: shunting there may give rise to dilated tortuous retinal vessels (plus disease), which is a poor prognostic indicator; regression (resumption of radial vascularization) or progression to neovascularization (stage 3 ) also occurs at the ridge. ${ }^{40}$

Histologically, the ridge is hypercellular and consists of a larger anterior collection of spindle-shaped cells in the nerve fibre layer (the 'vanguard'), and a variably present smaller posterior vascularized rearguard. ${ }^{41}$ Ashton, ${ }^{42} 50$ years ago, presumed that spindle-shaped ridge cells are the mesenchymal angioblasts that he posited built up the developing retinal vasculature, a view that is frequently cited by other researchers. ${ }^{43,44}$ Subsequent investigators suggested that the ridge is heterogeneous, consisting of a smaller population of vascular precursor cells in the rearguard, and a larger anterior, and possibly glial population in the vanguard. ${ }^{41,45}$ Additional suggestions include pericyte precursors, and accessory cells that serve a developmental function (eg, nutritional or biomechanical support) but do not persist beyond early development. ${ }^{16}$

Because of the importance of the ridge in the pathogenesis of ROP, we recently undertook a comprehensive immunohistochemical evaluation of ridge cells. We found that nearly all spindle-shaped cells that comprise the ridge vanguard are glial: they are primarily PAX2-positive astrocyte precursors and, to a far lesser extent, mature GFAP-positive astrocytes. Rare microglia are present in the ridge, whereas vascular endothelial cells and precursors are not. ${ }^{46}$

As noted above, immature astrocytes that lie just ahead of developing retinal vessels secrete VEGF and other cytokines that stimulate vascular extension. It seems possible that VEGF secretion by astrocyte precursor cells 

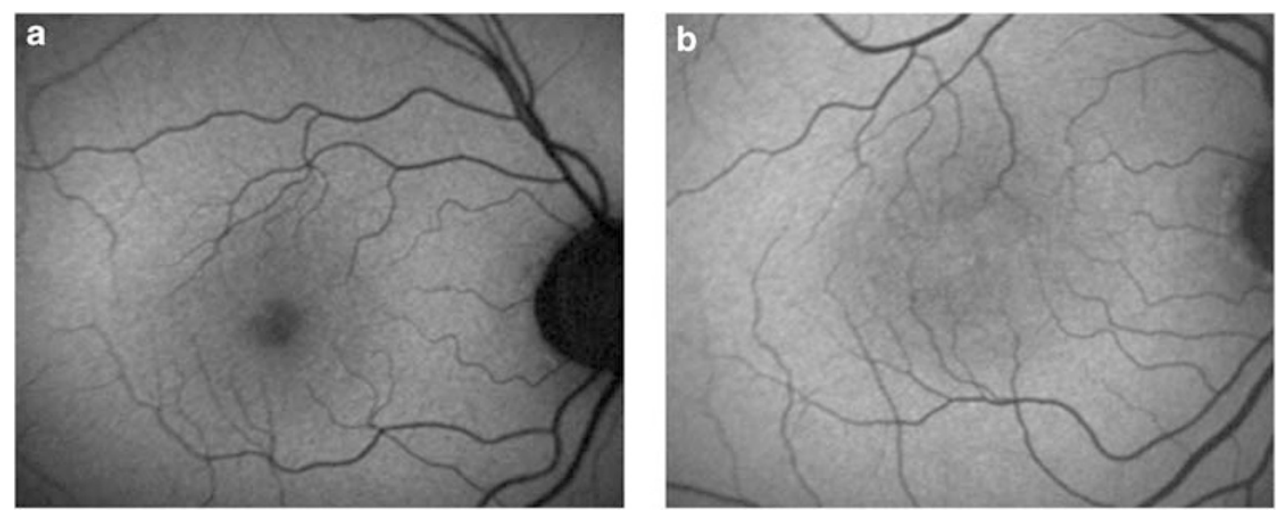

Figure 3 Macular pigments and foveal avascularity. (a) Autofluorescent image of a healthy human retina shows the normal dark spot roughly coextensive with the FAZ, due to blockage of subretinal fluorescence by macular pigments. (b) In a patient with macular telangiectasia, this central blockage is absent, indicating depletion of macular pigments. Reproduced from Helb et al, ${ }^{37}$ with permission of Wolters Kluwer Health. (c) The Opthalmic Communications Society, Inc.

in the ridge can stimulate neovascularization, which typically appears just posterior to the ridge. If this is the case, then laser ablation of the ridge might be beneficial in cases in which peripheral avascular retinal laser therapy is insufficient to cause regression of neovascular tissue. $^{47}$

Two processes may underlie genesis of a hypercellular ridge: (1) hyperplasia arises from glial cell division; and (2) astrocyte precursor cells accumulate focally due to interruption of their radial migration at the border of vascularized and avascular retina. Laboratory studies provide support for both possibilities, as proliferation is enhanced and migration reduced in mouse retinal astrocyte precursors in low oxygen. ${ }^{48,49}$ We detected modest cell proliferation in the ridge, suggesting that cell division at least partly contributes to ridge formation. We also detected very few astrocytic cells distal to the ridge, consistent with interrupted glial migration. ${ }^{46}$ Resolution of this issue requires analysis of cell proliferation in retinae with late stage 1 and early stage 2 ROP, when the ridge begins to form.

Retinal vascularization also arrests in experimental animals exposed to hyperoxia during the period of retinal vascularization. Subsequent return to normoxia results in retinal hypoxia and neovascularization. Oxygen-induced retinopathy (OIR) was first reported in mice, ${ }^{50}$ and has since been created in several other species, including cats, dogs, rats, and pigs. OIR is a highly valuable model for studying ROP and angiogenesis in general, but it lacks the critical ridge structure of ROP. Astrocytic hyperplasia does not occur at the vascular-avascular border in experimental OIR; rather, marked astrocytic degeneration (arising during the hyperoxic phase) occurs. ${ }^{51-53}$ The reason for this difference is unclear, but may reflect the observation that in primate development, peripherally migrating astrocytes lead growing vessels by a relatively short distance, whereas in mice astrocytic coverage of the retina is nearly complete at birth, when vessels are just beginning to enter the retina. ${ }^{1,4,5,15,17,18}$ Primate immature astrocytes are thus more localized to the vascular-avascular border, in which 'physiologic hypoxia' is greatest ${ }^{48}$ and hypoxia-driven interrupted migration and hyperplasia may create a ridge.

In conclusion, unique aspects of primate retinal vascularization include a more complex vascular pattern, a foveal avascular region, and specific glial responses to ischaemia. These features reflect novel neurovascular and gliovascular relationships and multiple endogenous antiangiogenic mechanisms that enhance our understanding of retinal development and may be clinically useful.

\section{Conflict of interest}

The author declares no conflict of interest.

\section{References}

1 Provis JM. Development of the primate retinal vasculature. Prog Retin Eye Res 2001; 20: 799-821.

2 Gariano RF, Iruela-Arispe ML, Hendrickson AE. Vascular development in primate retina: comparison of laminar plexus formation in monkey and human. Invest Ophthalmol Vis Sci 1994; 35: 3442-3455.

3 Connolly SE, Hores TA, Smith LE, D'Amore PA. Characterization of vascular development in the mouse retina. Microvasc Res 1988; 36: 275-290.

4 Dorrell MI, Aguilar E, Friedlander M. Retinal vascular development is mediated by endothelial filopodia, a preexisting astrocytic template and specific R-cadherin adhesion. Invest Ophthalmol Vis Sci 2002; 43: 3500-3510.

5 Fruttiger M. Development of the retinal vasculature. Angiogenesis 2007; 10: 77-88. 
6 Chang Ling T, Stone J. Factors determining the morphology and distribution of astrocytes in the cat retina: a 'contactspacing' model of astrocyte interaction. J Comp Neurol 1991; 303: 387-399.

7 Gerhardt H, Golding M, Fruttiger M, Ruhrberg C, Lundkvist A, Abramsson A et al. VEGF guides angiogenic sprouting utilizing endothelial tip cell filopodia. J Cell Biol 2003; 161: 1163-1177.

8 Uemura A, Kusuhara S, Wiegand SJ, Yu RT, Nishikawa S. Tlx acts as a proangiogenic switch by regulating extracellular assembly of fibronectin matrices in retinal astrocytes. J Clin Invest 2006; 116: 369-377.

9 Benjamin LE, Hemo I, Keshet E. A plasticity window for blood vessel remodelling is defined by pericyte coverage of the preformed endothelial network and is regulated by PDGF-B and VEGF. Development 1998; 125 1591-1598.

10 Sapieha P, Sirinyan M, Hamel D, Zaniolo K, Joyal JS, Cho JH et al. The succinate receptor GPR91 in neurons has a major role in retinal angiogenesis. Nat Med 2008; 14: 1067-1076.

11 Gariano RF, Hu D, Helms J. Expression of angiogenesisrelated genes during retinal development. Gene Expr Patterns 2006; 6: 187-192.

12 Risau W. Mechanisms of angiogenesis. Nature 1997; 386: 671-674.

13 Michaelson IC. Retinal Circulation in Man and Animals. Charles C Thomas: Springfield, IL, 1954.

14 Ashton NA. Retinal angiogenesis in the human embryo. Br Med Bull 1970; 26: 103-106.

15 Gariano RF, Sage EH, Kaplan HJ, Hendrickson AE. Development of astrocytes and their relation to blood vessels in fetal monkey retina. Invest Ophthalmol Vis Sci 1996; 37: 2367-2375.

16 Gariano RF, Iruela-Arispe ML, Sage EH, Hendrickson AE. Immunohistochemical characterization of developing and mature primate retinal blood vessels. Invest Ophthalmol Vis Sci 1996; 37: 93-103.

17 Fruttiger M. Development of the mouse retinal vasculature: angiogenesis vs vasculogenesis. Invest Ophthalmol Vis Sci 2002; 43: 522-527.

18 Chan-Ling T, McLeod DS, Hughes S, Baxter L, Chu Y, Hasegawa $\mathrm{T}$ et al. Astrocyte-endothelial cell relationships during human retinal vascular development. Invest Ophthalmol Vis Sci 2004; 45: 2020-2032.

19 Hasegawa T, McLeod DS, Prow T, Merges C, Grebe R, Lutty GA. Vascular precursors in developing human retina. Invest Ophthalmol Vis Sci 2008; 49: 2178-2192.

20 Song H, Zhao Y, Qi X, Chui YT, Burns SA. Stokes vector analysis of adaptive optics images of the retina. Opt Lett 2008; 33: 137-139.

21 Adams DL, Horton JC. The representation of retinal blood vessels in primate striate cortex. J Neurosci 2003; 23: 5984-5997.

22 Engerman RL. Development of the macular circulation. Invest Ophthalmol 1976; 15: 835-840.

23 Provis JM, Hendrickson AE. The foveal avascular region of developing human retina. Arch Ophthalmol 2008; 126: 507-511.

24 Springer AD, Hendrickson AE. Development of the primate area of high acuity, 3: temporal relationships between pit formation, retinal elongation and cone packing. Vis Neurosci 2005; 22: 171-185.

25 Provis JM, Penfold PL, Cornish EE, Sandercoe TM, Madigan MC. Anatomy and development of the macula: specialisation and the vulnerability to macular degeneration. Clin Exp Optom 2005; 88: 269-281.

26 Flower RW, McLeod DS, Lutty GA, Goldberg B, Wajer SD. Postnatal retinal vascular development of the puppy. Invest Ophthalmol Vis Sci 1985; 26: 957-968.

27 Provis JM, Sandercoe T, Hendrickson AE. Astrocytes and blood vessels define the foveal rim during primate retinal development. Invest Ophthalmol Vis Sci 2000; 41: 2827-2836.

28 Sandercoe TM, Geller SF, Hendrickson AE, Stone J, Provis JM. VEGF expression by ganglion cells in central retina before formation of the foveal depression in monkey retina: evidence of developmental hypoxia. J Comp Neurol 2003; 462: $42-54$

29 Snodderly DM, Weinhaus RS, Choi JC. Neural-vascular relationships in central retina of macaque monkeys (Macaca fascicularis). J Neurosci 1992; 12: 1169-1193.

30 Kozulin P, Natoli R, O'Brien KM, Madigan MC, Provis JM. Differential expression of anti-angiogenic factors and guidance genes in the developing macula. Mol Vis 2009; 15: 45-59.

31 Snodderly DM, Auran JD, Delori FC. The macular pigment. II. Spatial distribution in primate retinas. Invest Ophthalmol Vis Sci 1984; 25: 674-685.

32 Chew BP, Brown CM, Park JS, Mixter PF. Dietary lutein inhibits mouse mammary tumor growth by regulating angiogenesis and apoptosis. Anticancer Res 2003; 23: 3333-3339.

33 Izumi-Nagai K, Nagai N, Ohgami K, Satofuka S, Ozawa Y, Tsubota $\mathrm{K}$ et al. Macular pigment lutein is antiinflammatory in preventing choroidal neovascularization. Arterioscler Thromb Vasc Biol 2007; 27: 2555-2562.

34 Rodanant N, Bartsch DU, Bessho K, Freeman WR. Autofluorescence image in ocular albinism. Retina 2003; 23: 265-266.

35 van Genderen MM, Riemslag FC, Schuil J, Hoeben FP, Stilma JS, Meire FM. Chiasmal misrouting and foveal hypoplasia without albinism. Br J Ophthalmol 2006; 90: 1098-1102.

36 Abadi RV, Dickinson CM. Blue light hazard and aniridia. Br J Ophthalmol 1985; 69: 233-235.

37 Helb HM, Charbel Issa P, VAN DER Veen RL, Berendschot TT, Scholl HP, Holz FG. Abnormal macular pigment distribution in type 2 idiopathic macular telangiectasia. Retina 2008; 28: 808-816.

38 Eliassi-Rad B, Green WR. Histopathologic study of presumed parafoveal telangiectasis. Retina 1999; 19: 332-335.

39 Neuringer M, Sandstrom MM, Johnson EJ, Snodderly DM. Nutritional manipulation of primate retinas, I: effects of lutein or zeaxanthin supplements on serum and macular pigment in xanthophyll-free rhesus monkeys. Invest Ophthalmol Vis Sci 2004; 45: 3234-3243.

40 Kushner BJ, Essner D, Cohen IJ, Flynn JT. Retrolental fibroplasia. II. Pathologic correlation. Arch Ophthalmol 1977; 95: 29-38.

41 Foos RY. Retinopathy of prematurity. Pathologic correlation of clinical stages. Retina 1987; 7: 260-276.

42 Ashton N. Oxygen and the growth and development of retinal vessels. In vivo and in vitro studies. The XX Francis I. Proctor Lecture. Am J Ophthalmol 1966; 623: 412-435.

43 Kretzer FL, Mehta RS, Johnson AT, Hunter DG, Brown ES, Hittner HM. Vitamin E protects against retinopathy of prematurity through action on spindle cells. Nature 1984; 309: 793-795. 
44 Palmer EA, Phelps DL, Spencer R, Lutty GA. Retinopathy of prematurity. In: Ryan SJ (ed). RETINA. Mosby Press: St Louis, 2006, pp 1447-1474.

45 Cogan DG, Kuwabara T. Accessory cells in vessels of the paranatal human retina. Arch Ophthalmol 1986; 104: 747-752.

46 Young SL, Dalal R, Gariano R. Cellular composition of the ridge in retinopathy of prematurity. Arch Ophthalmol (in press).

47 Steinmetz RL, Brooks Jr L. Diode laser photocoagulation to the ridge and avascular retina in threshold retinopathy of prematurity. Retina 2002; 22: 48-52.

48 West H, Richardson WD, Fruttiger M. Stabilization of the retinal vascular network by reciprocal feedback between blood vessels and astrocytes. Development 2005; 132: 1855-1862.

49 Zhang Y, Porat RM, Alon T, Keshet E, Stone J. Tissue oxygen levels control astrocyte movement and differentiation in developing retina. Brain Res Dev Brain Res 1999; 118: 135-145.

50 Smith LE, Wesolowski E, McLellan A, Kostyk SK, D'Amato $\mathrm{R}$, Sullivan $\mathrm{R}$ et al. Oxygen-induced retinopathy in the mouse. Invest Ophthalmol Vis Sci 1994; 35: 101-111.

51 Downie LE, Pianta MJ, Vingrys AJ, Wilkinson-Berka JL, Fletcher EL. AT1 receptor inhibition prevents astrocyte degeneration and restores vascular growth in oxygeninduced retinopathy. Glia 2008; 56: 1076-1090.

52 Dorrell MI, Aguilar E, Jacobson R, Trauger SA, Friedlander $\mathrm{J}$, Siuzdak $\mathrm{G}$ et al. Maintaining retinal astrocytes normalizes revascularization and prevents vascular pathology associated with oxygen-induced retinopathy. Glia 2010; 58: 43-54.

53 Stone J, Chan-Ling T, Pe'er J, Itin A, Gnessin H, Keshet E. Roles of vascular endothelial growth factor and astrocyte degeneration in the genesis of retinopathy of prematurity. Invest Ophthalmol Vis Sci 1996; 37: 290-299. 